\title{
EL GRAN MADRID EN VIAS DE CONSTITUCION
}

La secuela obligada de las aglomeraciones urbanas es la formación de nuevos tipos de gobierno local. Los vecindarios de los Ayuntamientos enclavados en la aglomeración dependen de autoridades administrativas distintas; pero la comunidad de intereses y de vida engendra entre ellos lazos y relaciones que determinan a fortiori la creación de normas jurídicas y económicas iguales, cual si todos los vecindarios integraran uno solo.

Para el logro de esa finalidad se ha apelado a diversos arbitrios. En Viena, que es donde por vez primera se pretendió abordar y resolver el problema, se implantó el sistema de anexión pura y simple; en Berlín se ha creado un organismo que si bien somete a todos los elementos locales de la aglomeración a una superior autoridad federal, deja a los componentes de la mancomunidad un cierto margen de autonomía; otras aglomeraciones, en fin, como Londres, prefieren un sistema mixto y complicado, muy a tono con las particularidades de aquel país, tan ducho en las tareas de hermanar instituciones e ideas anacrónicas con las más atrevidas y modernas.

Aunque mencionamos sólo Viena. Berlín y Londres, no son éstos los únicos casos dignos de estudio. Hay otros, también muy aleccionadores, que ofrecen características peculiares. Los de Praga, los de las ciudades belgas, los de las italianas, Buenos Aires, Nueva York, etcétera, son ejemplos de gobjerno de aglomeraciones urbanas.

En el orden cronológico Viena aparece en primer lugar entre las ciadades donde se estableció el régimen de aglomeración metropolitana. Se planté el problema en 1896; a la sazón, la bella capital del Danubio era la cabecera del Imperio austro-húngaro; el perimetro municipal ocupaba 5.540 hectáreas y la población excedía de 376 millón y medio de habitantes fuera del área urbana, más de medio 
millón de almas pertenecía a otras Municipalidades, aunque su existencia estaba unida a la de la Metrópoli; por otra parte, a Viena le faltaba campiña, necesitaba "pulmones". Para conjurar esas deficiencias y sentar los jalones de una organización adecuada, incorporáronse en los años de 1896, 1904 y 1910 amplias superficies, que en junto medían unas 22.000 hectáreas; la ciudad aument6 su perímetro en un 400 por 100 . Los nuevos territorios, con más de 600.000 habitantes; fueron anexionados a Viena; al frente de la $\mathrm{Mu}$ nicipalidad se colocó un Ayuntamiento con 165 representantes. Las funciones ejecutivas confiáronse a un Comité ejecutivo de 21 miembros, con un burgomaestre y dos adjuntos y una dirección técnica, auxiliada de altos empleados. Sin embargo, la anexion no fué absoluta, pues dividió la ciudad en 21 distritos que funcionan con relativa autonomía, dirigidos por pequeños Ayuntamientos de tres a 18 individuos y que entienden las pequeñas cuestiones de los distritos respectivos.

La administración de Londres tiene la característica flexibilidad de la administración británica. Gracias a las leyes unificadoras de 1855, se simplificó considerablemente el régimen comunal del Reino Unido; entonces intervenían en el Municipio londinense alrededor de 300 corporaciones y más de 11.000 personas. Creóse el "Gran Metropolitan Board of Korks". Y en 1888 añadiéndose terrenos de los condados de Kent, Surrey y Middless, se organizó el "London County", que sustituyó al Metropolitan, adjudicándosele más facultades. Integran el "London County" 28 distritos, procedentes de las viejas comunas. El Concejo de la "City of London" fórmanlo 200 miembros, presididos por el Lord Maier. Incumben al Concejo los servicios de Grandes colectores, Higiene pública, Viviendas obreras, Parques y Jardines y espacios libres, Enseñanza industrial y técnica, Teatros y espectáculos en general, Aprobación de los empréstitos de las autoridades inferiores y Enseñanza pública.

Los "burós" metropolitanos están regidos por consejos formados por grupos de 20 a 60 miembros y un número de "Aldermen", equivalente a la sexta parte del Concejo. Sus funciones son: Caminos vecinales, Alumbrado, Recogida de basuras, ateniéndose a los reglamentos de la superioridad; Habitaciones insalubles, Policía de alimentos, Expropiaciones modestas para viviendas obreras, Baños y Lavaderos públicos, Bibliotecas públicas y Cementerios.

Algunos de los más importantes servicios metropolitanos están centralizados y regidos por Comités especiales, como el del Abastecimiento de aguas potables, el de Transportes en común, el de Bene- 977 
ficencia y Asistencia Social, el de Alienados y el de Protección de niños.

La organización del Gran Berlín es indudablemente la más completa. El Gran Berlín agrupa 94 corporaciones locales, ocho municipios urbanos; 59 rurales y 27 señoríos de procedencia feudal. Todos constituyen una sola entidad. Al frente de ella figura el Gran Consejo, integrado por 225 miembros. Dirígelo el "Magistrat", del que forman parte 30 individuos, de los cuales 12 , por lo menos, reciben retribución: La presidencia corre a cargo del Burgomaestre. Para el más eficaz funcionamiento divídense en comisiones especiales formadas por individuos del "Magistrat".

Junto a este numeroso y superior Consejo funcionan 20 pequeños Ayuntamientos, que corresponden a otros tantos distritos. Cada Ayuntamiento consta de 15 a 45 miembros, según la importancia del distrito; tiene un presidente $\mathrm{y}$ un vicepresidente.

La superficie del Gran Berlín mide 49.981 hectáreas y se calcula que podrá recibir una población de siete millones de almas. En 1875, a raíz de vincular en Berlín la capitalidad del Imp̉erio germano, se dictaron leyes para constituir el Gran Berlín; ni esta tentativa ni las hechas con la ley de 1911 dieron el fruto apetecido. En la segunda década del siglo en curso promulgóse la ley que dió por resultado la formación de esta entidad administrativa; sin embargo, halláronla defectuosa, y hacia 1930 ó 31 se modifico. A pesar de que es seguramente la organización local de esta clase más completa, los municipalistas no la consideran perfecta y antes de la guerra hablaban ya de introducir nuevas modificaciones.

Como antes indicamos, funcionan otros organismos locales adecuados para el régimen de las aglomeraciones urbanas. La del Gran Praga es de las más antiguas; se constituyó en 1920; consta de 17 distritos, cada uno de los cuales actúa como si fuera un pequeño Ayuntamiento, a semejanza de los de Berlín. El Concejo lo forman 100 ediles, dirigidos por una comisión ejecutiva de 24 .

En Italia han adoptado el régimen que esbozamos, entre otras capitales, Milán, Génova, Roma y alguna otra de las ciudades de mayor población.

En Bélgica, los trabajos para organizar el Gran Bruselas, agrupando las 19 comunas del aglomerado comenzaron antes de la actual guerra. La tarea prosigue, y se supone que el Gran Bruselas reunirá más de 1.000 .000 de almas. A pesar de los estragos de la trágica pugna y de las anormalidades propias de la excepcional situa378 ción que Bélgica atraviesa, los gobernantes se ocupan con el interés 
y la diligencia que las circunstancias les permiten de extender el. sistema de gobierno de grandes ciudades a Amberes, donde se han realizado reformas de trascendencia; Lieja, Gante, Charleroi y alguna otra población de las de primera línea.

En Suiza se practica el régimen de aglomeración en Ginebra.

París, que inició hace una veintena de años los estudios preliminares para formar el Gran París sobre la base de encerrar en su perímetro todos los Municipios del departamento del Sena y varios más de los contiguos, no ha interrumpido la labor más que durante la época más angustiosa de la guerra. Se continúa trabajando, aunque a ritmo lento. $\mathrm{Y}$ siguen siendo de aplicación las ideas y orientaciones defendidas por Enrique Sellier, el gran municipalista galo, tan conocido por sus brillantes intervenciones en los Congresos Internacionales de Ciudades y de Viviendas para las clases pobres.

Nueva York tiene también la organización de las aglomeraciones. Abarca cinco enormes ciudades, y ya en 1940, antes de la guerra, concentraba más de diez millones de habitantes; era la ciudad gigante mayor del orbe. Es de presumir que la incrementación persista.

Tokio y Moscú funcionan asimismo en régimen de gran aglomeración urbana. La capital nipona, que ha poco suma seis millones de almas, era la tercer ciudad gigante del mundo-sólo le aventajaban Nueva York y Londres-; acusa en su reciente censo otro aumento de un millón; tiène, consiguientemente, siete millones de pobladores. Y Moscú, que al producirse la revulución de 1917 perdió más. de medio millón de habitantes-de 1.400 .000 descendió a 900.000-, ha llegado a colocarse en lo que respecta a la población a la altura de París y Berlín.

En este proceso de constitución de organismos del tipo que examinamos figura un caso que debe inspiramos excepcional interés: el del Gran Buenos Aires. La capital argentinu era hace poco la ciudad de habla castellana más numerosa; había rebasado de los dos millones de almas. Hoy cuenta más de 2.600.000. Pero no se circunscribe a ser una gran ciudad, aspira a catalogarse entre las ciudades gigantes. Para ello estudia la constitución del Gran Buenos Aires, para lo cual aspira a la incorporación íntegra a la capital de las zonas de la Avenida, de las lomas de Zamora, Vicente López, San Isidro, San Fernando, San Martín, Cinco de Septiembre y a la incorporación parcial de las zonas de las Conchas, Almirante Brown, Quimes y Manzana. La población de los territorios citados es de más de un millón de almas; de suerte que. una vez ultimada la organización del aglomerado bonaerense, la ciudad del Plata entrará por derecho pro- 379 
pio en la categoría de las urbes gigantes, lo que habremos de considerar como un galardón para la raza hispana, ya que evidenciará su capacidad para estos magnos empeños de la civilización.

Con estas someras indicaciones no pretendemos, naturalmente, hacer el estudio acabado que la trascendıncia del problema exige.

Sólo aspiramos a dar una ligera idea de la cuestión y abrir cauces a la búsqueda de elementos de juicio para acometer la formación del Gran Madrid con las mayores garantías de éxito.

Otro elemento de juicio hállase en los materiales reunidos en los Congresos Internacionales de Ciudades de Gante de 1913 y de París de 1925, en los que se formularon conclusiones que proyectan abundante luz acerca del problema. Los ponentes fueron Ernesto Baes, en Gante, y Seltaer, en París.

Parece que el problema del Gran Mudrid se aborda ahora a fondo. Hace años, muchos años, que debí abordarse. Ahora bien, no confundir esta cuestión con la de los antiguos pueblos sexmeros. Es frecuente que se hable de que el Gran Madrid reconstituye el régimen sexmero de la edad medioeval. Es un error. Los pueblos sexmeros no pertenecían a la aglomeración urbana matritense, entre otros motivos, por el poderosísimo de que entonces la tal aglomeración no existía. Madrid era una modesta villa, casi una aldea.

Los pueblos sexmeros, o eran donaciones hechas por los monarcas a los Municipios de realengo en agradecimiento de los servicios prestados por los Municipios-particularmente por la ayuda de las milicias concejiles en la guerra - o sometimiento de los pueblos indedefensos a las villas amuralladas para acogerse a sus fortalezas y eludir las asechanzas de la morisma. Pero entre los pueblos sexmeros y la villa metropolitana no existía siempre la coincidencia de intereses que constituyen las características de las aglomeraciones.

El sexmo de Madrid no ha tenido siempre la misma demarcación; ha variado a gusto de los reyes. En el siglo XVII eran tres los Sexmeros que funcionaban en el término jurisdiccional de Madrid: el primero correspondía a Vallecas y comprendía Vicálvaro, Ambroz, Coslada, Ribas, Vaciamadrid, Velilla, Rojas, Canillas, Canillejas, Hortaleza, Chamartin, Fuencarral, San Sebastián de los Reyes y Fuenlabrada; el segundo era el de Villaverde y constaba de los pueblos de Getafe, Fuenlabrada, Torrejón de la Calzada, Casarrubielos, Humanejos y Perales; el tercero, Aravaca, con Rozas, Majadahonda, 380 Boadilla, Alcorcón, los Carabancheles y Leganés. 
Como puede comprobarse, varios de los pueblos sexmeros no pertenecen hoy al aglomerado y hasta han desaparecido del mapa municipal, y otros que figuran en la aglomeración no están por los motivos históricos que estuvieron en el sexmo, sino por razones económicas, sociales y comunales propias de las circunstancias que regulan la vida local moderna.

Tampoco el problema que tratamos es el de la extensión de Madrid. Nuestra ciudad ha vivido hasta el tercio final de la pasada centuria encerrada en los precarios límites de una cerca miserable-cerca, no muralla-que se trazó en tiempos de Felipe IV y que acabó de edificarse un siglo después; las 8.000 casas y las 150.000 almas que poblaban Madrid se debatían en angosturas y hacinamientos, que se traducían en índices mortuorios superiores al 50 por 1.000 -33 puntos más que ahora-. Conocida es la frase de Larra en 1836; escribía que la población se escapaba de la cerca como el chocolate de un puchero estrecho en pleno hervor. Pretendióse resolver este problema de "extensión" en 1846 con las iniciativas del Ministro Pidal, en mal hora rechazadas por el Ayuntamiento de Madrid, equivocadamente aconsejado por Mesonero Romanos. Tampoco dieron juego las primeras leyes de Ensanche. En cambio tuvo notoria eficacia el derribo de la cerca efectuado por Nicolás María Rivero en 1868. Estos derribos libertaron a Madrid de sus cadenas, mas restaba la ingente tarea de urbanizar los alrededores de la ciudad y los caminos de acceso; a pesar de la última ley de Ensanche, deficiente aunque aprovechable, y los buenos propósitos de algunos ediles y alcaldes, el asunto no se ha resuelto. En lugar de emprender grandes obras, se han formulado grandes proyectos y hasta se convocó un concurso internacional y se montó una oficina de urbanismo municipal, por la que han desfilado buen golpe de expertos de la villa.

Digamos, como remate, que no sólo no se ha tocado el problema del Gran Madrid, sino que ni siquiera se ha abordado en serio el del arreglo del perímetro de Madrid, que durante mucho tiempo se denominó del extrarradio, y que en los años últimos se pretendía solucionar mediante la formación de un plan comarcal.

\section{***}

Los datos que siguen son antecedentes obligados para conocer cómo en España se produce el fenómeno de concentración de población en los grandes centros urbanos $y_{\text {, }}$ consiguientemente, de la formación de aglomeraciones, cuyo funcionamiento hay que someter a reglas y administraciones unificadas o, por lo menos, mancomuna- 381 - 
das, en bien de la eficacia de los servicios, de la salubridad pública, del ornato y de la economía de las municipalidades.

El cuadro adjunto acredita cómo se hacinan las gentes en las grandes ciudades, las que tienen más de $\mathbf{1 0 0 . 0 0 0 ~ h a b i t a n t e s . ~}$

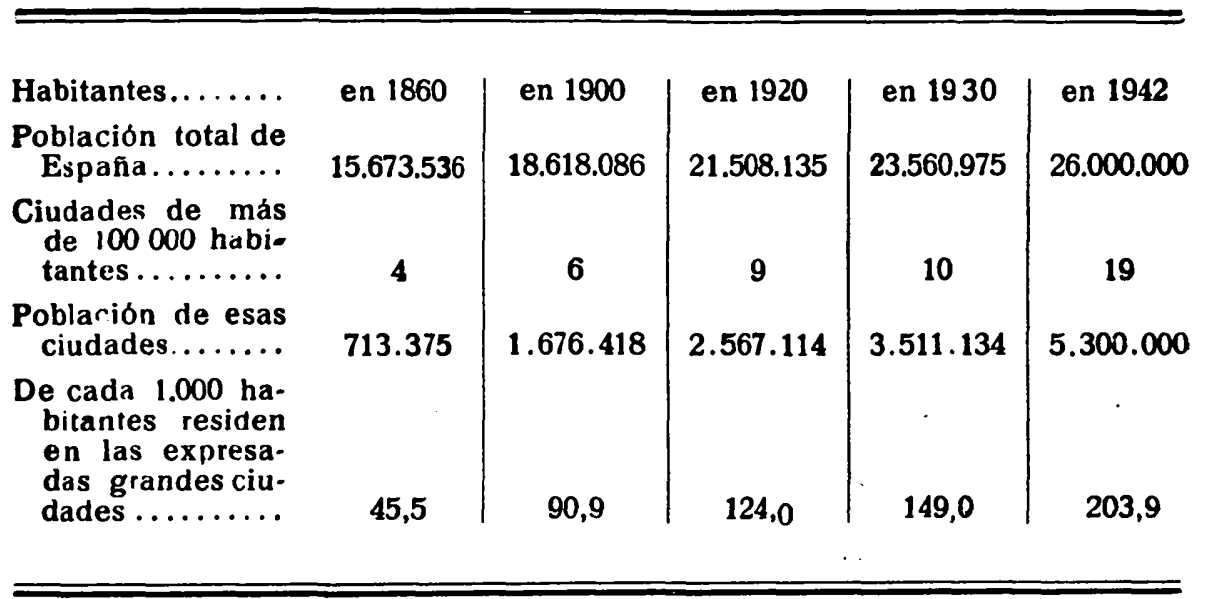

(Las cifras correspondientes a 1942 son aproximadas, pues todavía no se han divulgado las estadíticas de población del referido año. Computamos como grandes ciudades-de más de 100.000 almas-a las siguientes: $\cdot$ Madrid, Barcelona, Valencia, Zaragoza, Málaga, Bilbao, Murcia. Granada, Córdoba, Las Palmas, Valladolid, Palma de Mallorca, Coruña, San Sebastián, Cartagena, Santander, Alicante y Cádiz.)

Concretemos ahora los poblados o Municipios que forman la aglomeración matritense y que han de integrar en su día el Gran Madrid:

MUNICIPIOS

-

Madrid

Aravaca

Barajas

Canillas

Canillejas ..............

Carabanchel Alto

\section{Extension \\ Hectáreas}

6.652

1.127

1.179

1.006

2.479
Población

Habitantes

1.170 .000

1.305

2.124

21.644

4.816

11.334 


$\begin{array}{ll}\text { Extensión } & \text { Población } \\ \text { Hectáreas } & \text { Habitantes }\end{array}$

Idem Bajo $\ldots \ldots \ldots \ldots \ldots \quad 1.206$

29.933

Chamartín de la Rosa ..... 1.384

62.190

El Pardo ............. 19.638

2.460

Hortaleza . . . . . . 1.362

1.054

Fuencarral .......... 5.439

13.184

Pozuelo de Alarcón

2.463

2.400

Vallecas ................

7.236

67.000

Vicálvaro ........... 4.506

21.415

Villaverde

2.920

7.537

No se tomen estas cifras como rigurosamente exactas. Por efecto de la guerra ha habido grandes cambios en ciertas localidades, particularmente en las que fueron frente de batalla. Aunque la normalidad se restablece y en varios Municipios la población se incrementa y rebasa la que había en 1936, en otros todavía no ha llegado a las cif:as de dicho año. Sin embargo, todo induce a suponer que muy pronto habrá en todos los pueblos del aglomerado más habitantes que tuvo nunca.

La técnica municipal de Madrid se pronuncia por un sistema de gobierno mixto, en el que se conjuga la anexión inmediata de ciertos pueblos y de sectores de otros y la formación de mancomunidades de servicios con la fracción no incorporada de esos Municipios y con los Municipios adscritos a la zona de influencia del aglomerado y que conservaron para los servicios no mancomunados y la administración general completa autonomía.

Propone la incorporación de los pueblos de Chamartín, Villaverde, Canillas y Carabanchel Bajo y la de ciertos sectores de los pueblos de Hortaleza, Barajas, Coslada, San Fernando, Ribas del Jarama, Carabanchel Alto, Leganés, Getafe, Pozuelo y Aravaca. La superficie de Madrid con las anexiones dichas se aproximará a 20.000 hectáreas y su población a 1.500 .000 almas.

Ahora bien, si prosiguen las anexiones propuestas, ếrea del Gran383 
Madrid llegará a ocupar 50.000 hectáreas y su población excederá en breve plazo de dos millones de habitantes.

En los trabajos urbanísticos que esboza la técnica municipal se comprende un espacio que tendrá 37 por 30 kilómetros de superficie. Aún no se han concretado la obras que han de realizarse; pero del avance hecho por los expertos del Municipio resulta que el volumen de gastos que en principio se calcula es el que a continuación detallamos:

SER VICIOS

A nexion e s: Abastecimiento de aguas potables. Alcantarillado... Expropiaciones y pavimentación.. Alumbrado ............. Edificios y obras de arquitectura.

Zonas agregadas: Aguas y alcantarillado. . . . . . . . . . . . Pavimentaciones, alumbrado, incrementaciones forestales .. . . . . $\quad \mathbf{5 5 . 0 0 0 . 0 0 0}$ Gasto zonas agregadas 261.700 .000 595.000 .000 79.000 .000 211.000 .000 1.146.700.000

Agrupaciones de térmiros 100.000 .000

Total general ..........

1.246 .700 .000

No se computa en este avance de presupuesto, ni los gastos de reforma interior de la ciudad ni los de la conclusión del Ensanche, ni los de ciertos servicios muy insuficientemente dotados. Por ejemplo, el coste del arreglo del Interior no bajará de 150.000 .000 de pesetas y el del Ensanche de 50.000.000. Respecto al déficit de servicios habrá que invertir para enjugarlo sumas enormes: en escuelas, más de 50.000.000; en limpieza, más de 35.000 .000 ; en el tratamiento de aguas residuales, más de 25.000 .000 ; en construir viviendas para las clases modestas, más de 500.000 .000 ; en transportes en común, más de 50.000.000. En suma, la contrucción del Gran Madrid 384 y el arreglo de sus zonas interiores y de Ensanche y la puesta en mar- 
eha de sus servicios básicos exigirá un desembolso de 2.800.000.000 de pesetas.

Aunque la procedencia de los cálculos expuestos garantizan su seriedad y permiten augurios dignos de crédito, sería temerario recogerlos como rigurosamente verídicos.

Las obras del Gran Madrid han de acordase por el organismo estatal-municipal que se constituirá en breve. Madrid tendrá, es lógico, intervención importante, mas también la habrá del Estado y sus órganos más representativos, Diputación Provincial y de los Ayuntamientos que radican en la zona del Gran Madrid.

Precisamente en los actuales momentos se está forjando el instrumento que se ha de encargar de formular los proyectos del Gran Madrid y de convertirlos en realidades. Habrá en el referido organismo representantes de los Ministerios de la Gobernación cuyo titular será el presidente nato. Habrá también un vicepresidente que sustituirá al ministro en caso de ausencia. Los Ministerios de Hacienda, Industria y Comercio, Agricultura, Educación Nacional, Guerra, Marina y Aire, nombrarán delegados ad hoc y pertenecerán asimismo a la Junta los Directores de Regiones Devastadas, Arquitectura, Sanidad, Ferrocarriles y Obras Hidráulicas; el Gobernador, el Presidente de la Diputación, el Alcalde y varios ediles de Madrid; dos representantes de los Municipios afectados directamente por el Gran Madrid; el Fiscal Superior de la Vivienda, un representante de la Cámara de la Propiedad. un técnico jurídico y otro financiero.

El Consejo actuará en sesión plenaria para discutir y resolver determinados asuntos; mas para la labor práctica y urgente se elegirá un Comité ejecutivo, bajo la dirección del vicepresidente, que será el gerente de la Comisión; constituirán el Ejecutivo los representantes de los Ministerios de Hacienda, Industria y Comercio, el delegado del Concejo madrileño y el de los Ayuntamientos de la provincia interesados en la empresa.

El Ayuntamiento de Madrid elaborará en un plazo breve el proyecto de las obras que estima necesario llevar a efecto, acompañando el correspondiente plan financiero. Este extremo se halla casi resuelto, pues el Concejo se ha adelantado con el proyecto general, cuyas líneas generales hemos expuesto.

Los Municipios no anexionados podrán presentar también sus proyectos. Y la Dirección de Regiones Devastadas, en relación con la comarca comprendida en el Gran Madrid y sometida a su control. 385 
El Estado colaborará a la empresa, abriendo los créditos necesarios en concepto de anticipos reintegrables.

Complemento de estas disposiciones serán las que se dicten para instaurar una política del suelo que cierre el paso al agio de terrenos y las que implanten con ejemplar rigor las servidumbres estéticas; que defiendan de los ataques de la codicia y de la ignorancia los monumentos artísticos e históricos y los parajes bellos o simplemente pintorescos.

$$
\text { ** }
$$

Adviértase que a los legisladores, de momento, les preocupa más quiénes han de hacer el Gran Madrid y con qué elementos lo han de construir que el sistema que ha de aplicarse para el gobierno futuro de la nueva entidad local.

De lo expuesto se infiere, desde luego, que, por lo que respecta a los pueblos y zonas que se han de incorporar al aglomerado, oficialmente se aplicará el sistema de anexión.

Para la implantación de los servicios mancomunados con los $\mathrm{Mu}$. nicipios no anexionados, regirá el sistema federativo. Es decir, propónese emplear un sistema mixto, aunque todavía no se puede determnar concretamente cómo se constituirán las mancomunidades ni su funcionamiento.

Sobre las normas jurídicas que han de regular el gobierno del Gran Madrid, es prematuro cuanto se diga. En la ley Municipal vigente-art. $40^{\circ}$ - se reconoce la facultad de las ciudades de más de 100.000 almas a incorporarse, con aprobación de la Superioridad, zonas colindantes de caserío adscritas a otras autoridades administrativas, y se habla del derecho del aglomerado madrileño a constituir el Gran Madrid; pero ello. aparte de adolecer del defecto de la yaguedad, ofrece, en las circunstancias presentes, base muy endeble. Estamos, como es sabido, en víspera de que las Cortes aprueben una nueva ley municipal. Esta situación no es propicia para lanzarse a la aventura de establecer el gobierno del Gran Madrid. Esperemos la nueva ley. Por otra parte, esta demora, que no ha de ser larga, no es obstáculo para que el Gran Madrid comience a construirse.

Mariano Garcfa Cortés 